\title{
1 Instead of Introduction: Why Is Stakeholder Management Necessary and Possible in the Present Context?
}

\author{
Why Is Stakeholder Management Necessary Now, in the \\ Present Context?
}

\section{Organizational Arguments}

1 Perception and understanding of organizations, including companies of course - as social constructions. This means that they are artefacts created by human beings to serve their ends. They are shaped by human purposes, and they do not exist interdependently of human minds and actions. Companies are systems of human action in which means and ends are guided by intentions, strategies, and hoped-for incomes. They are in effect created by meaning with a rich tapestry of cultural rules, roles, and intentions (Coghlan, 2016).

2 Companies should - according to a recent study (Schwartz et al., 2019) - reframe the future of work, with the aim of generating more value and meaning for the customer, the workforce and other partners, and greater earnings for the company over time. In order to succeed with this vision, organizations must shift focus from company to customer, workforce, and other important stakeholders.

3 Development of a new type of company focused on knowledge - as resource, product, asset, and competitive advantage - which are quite different compared with the classical capitalist company; it is called a knowledge-based company.

4 Companies' contextualization by amplification of the external environment influences their objectives, resources, activities, functionality, performance, and sustainability on concomitantly with the multiplication and acceleration of the companies' inputs and outputs.

5 Awareness that financial performance should no longer be the sole pursuit of enterprises. Companies - according to Ignatius (2019) are being pushed to consider the interests of all their stakeholders, including employees, customers, and the community, not just those of their shareholders. 


\section{Instead of Introduction}

6 Intellectual capital plays a decisive role in the survival, functioning, and development of modern, knowledge-based companies.

7 The resources of a large proportion of the companies have changed profoundly in recent decades through:

- the emergence of two new categories of resources - information and knowledge;

- the components, the structure, and the functionality of "classical" resources - human, technical-material, and financial - have substantially changed;

- the human resource, very closely associated with information resource and knowledge resource, has a major role in modern organizations, much more than in classical companies.

8 Companies' activities have changed enormously in recent decades through:

- the formation of consistent activities focused on the creation, purchasing, use, share, valorization, etc. of knowledge; all these operations constitute the content of the new company knowledgefunction; this function is a transversal company function, different from vertical company functions (research and development, commercial, production, finance and accounting, and human resources);

- the content and dynamics of classical activities (supply, production, sales, accounting, finance, etc.) have also changed profoundly;

- human resources training, because of its size and major impact within an organization, gradually becomes - especially in largeand medium-sized companies - a distinct company's function fulfilled and partially externalized outside the organization.

9 Modern companies based on knowledge - this is quadro-dimensional, trying to achieve concomitantly four types of objectives:

- economic;

- social;

- ecological;

- educational.

10 A knowledge-based society is an ecosystem presenting the following features:

- a system made up of interactive parts that act together;

- a multidimensional community - human, economic, and ecological;

- networking endogen complex;

- a system interconnected with other systems and with its environment. 
11 The background of the performance and sustainability of a knowledge-based company is represented by the sustainability diamond based on knowledge (Figure 1.1).

12 Manifestation of the new organizational paradox was discovered by Hamel (2009) - the organization should become more adaptable, innovative, and inspirational, without being less focused and disciplined or less oriented toward performance.

13 The 2020 Future of Leadership Global Executive Study and Research Report finds that leaders may be holding on to behaviours that might have worked once but now stymie the talent of their employees. "Organizations must empower leaders to change their ways of making to succeed in a new digital economy" (Ready, Cohen, Kiron, \& Pring, 2020).

14 Awareness of the fact that the success of a firm is determined by its ability to establish and maintain relationships within the entire stakeholder network (Post, Preston, \& Sachs, 2002).

15 In the context of the pandemic, in the majority of companies, the connection and collaboration with many important external stakeholders, especially the customers, suppliers, bankers, and local communities, have been affected and need to be restored on a new basis taking into consideration the "new normality".

16 Deterioration in many companies of work relationships and cooperation between internal stakeholders - particularly between managers and subordinates - because of the massive increase in work online, social distancing, and other major changes caused by the COVID-19 pandemic. In order to restore good and even more performant work relationships between shareholders, managers, and subordinates, their approach should be reconsidered and rebuilt against a new and more motivational and innovative background.

17 Frequently, the survival of companies that are mostly affected by the COVID-19 pandemic is not possible without implications for stakeholders. In many countries, even the state becomes a major stakeholder for companies, developing national strategies and policies, focused on helping them to survive and to continue to work, making products and services, and protecting jobs and maintaining their capacity to generate incomes for the state budgets in the following period. Many states - and EU states are a very good example - have allocated huge amounts of money as grants and subvention credits, by subsidizing the costs for companies and the population.

18 Companies' reinvention taking in consideration the multiple changes and challenges occurred at mondo, macro, and micro systems. A recent study suggested that it is no longer about how companies should thrive, but rather how they must reinvent themselves to survive, because that is the key issue today (Weill \& Woerner, 2018). 

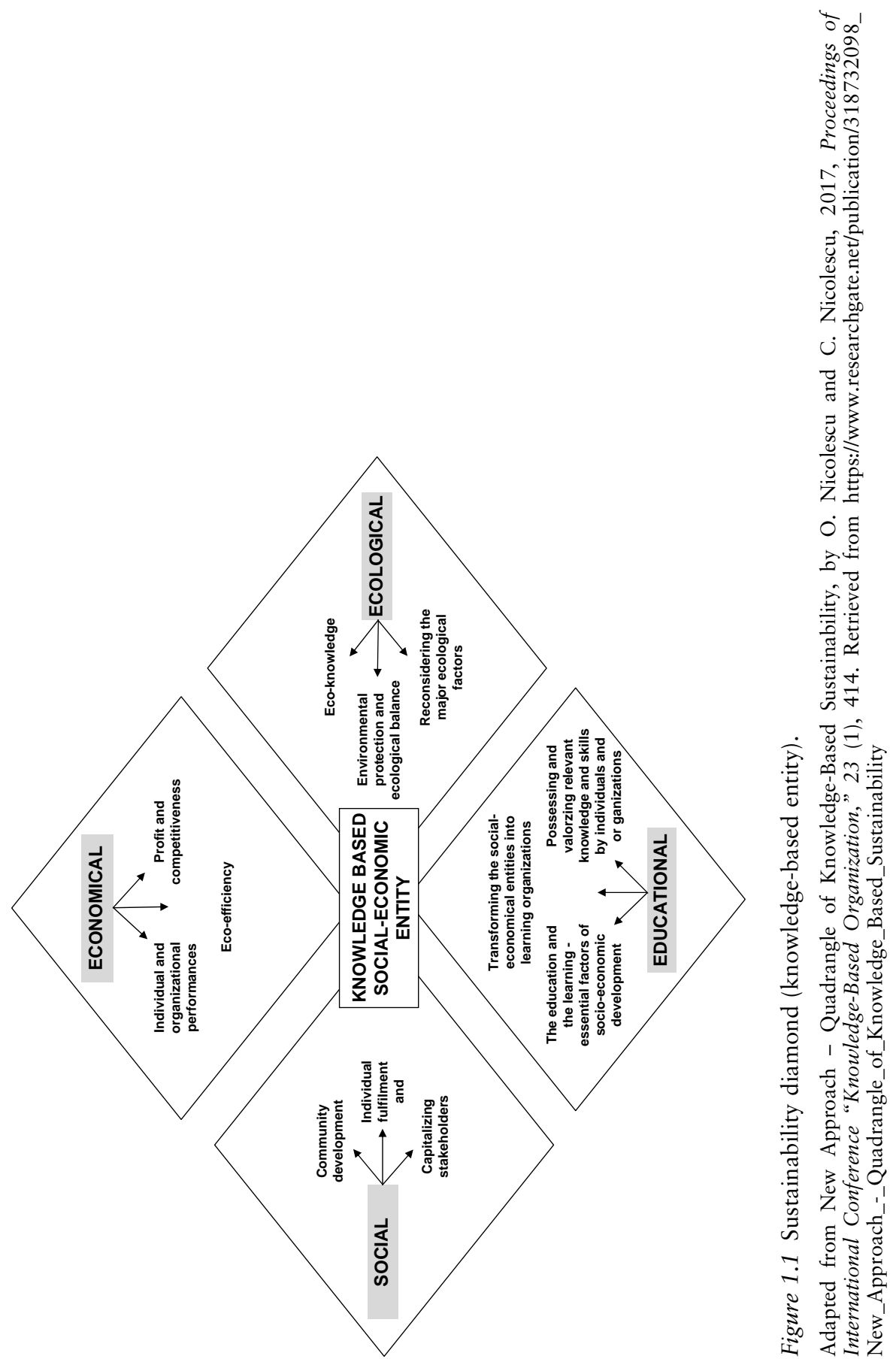


\section{Managerial Arguments}

1 Awareness of the existence of a comprehensive network of stakeholders - inside and outside companies - who have a major impact on their functionality, performance, and sustainability.

2 Traditional management, still predominant in the majority of companies, is based on the absolute primacy of the owner or shareholders' interests, with the needs and expectations of other stakeholders being ignored or only sporadically taken into consideration. A partial exception to this refers relatively often to companies' top managers.

3 In a recent study, well-known specialists Bailey, Reeves, Whitaker, and Hutchinson (2019) asked for indirect forms of management instead of command-and-control techniques.

4 It is - as Schein and Schein (2019) asserted - time for a new model, one that is built on close professional relationships, openness, and trust.

5 The potential of large number of the companies' endogenous stakeholders - managers and especially executants - is used for sustainable organizational development only to a small extent.

6 The traditional managerial relationship, i.e. manager-subordinate involving two of the most numerous and important company stakeholders, which is based on hierarchy and on the "strong" authority of the manager - is not sufficiently performative in the majority of organizations. As a consequence, in many companies, new managerial elements have been developed based on participation, flexibility, collaboration, and strategic agility, which may solve this problem only partially and not sufficiently.

7 The potential of most companies' exogenous stakeholders - clients, suppliers, investors, bankers, consultants, etc. - is frequently ignored or used only to a small degree. Because of this situation, these stakeholders do not contribute enough to generating value added for the company and to obtaining competitive advantage.

8 The ascertainment by many reputable specialists of the need to elaborate and to practice a new type of management that is radically different from the management predominant in the present management focused on stakeholders. This idea is very well formulated by the renowned Freeman $(2017$, p. 7$)$ in the foreword of a well-known book edited by Andriof, Waddock, Husted, and Rahman (2017): "the need for a new era of management thinking and one based on the idea of stakeholders. We need to rewrite management theory and practice".

9 Reconceptualization, based on the stakeholder theory, of a firm as a "multi-purpose entity" (Crane, Palazzo, Spence, \& Matten, 2014). This reconceptualization "opens" the door for "de facto" 
integration of the stakeholders in the company's strategy, functioning, and performance.

10 Refocusing of the top managers' cooperation on all stakeholders. "Statement on the Purpose of Cooperation" (International Council for Small Business, 2019), adopted by 185 leading USA CEOs in 2019, states: "We share a fundamental commitment to all of our stakeholders. We commit to:

- Delivering value to our customers. We will further the tradition of American companies leading the way in meeting or exceeding customer expectations;

- Investing in our employees. This starts with compensating them fairly and providing important benefits. It also includes supporting them through training and education that help develop new skills for a rapidly changing world. We foster diversity and inclusion, dignity and respect;

- Dealing fairly and ethically with our suppliers. We are dedicated to serving as good partners to the other companies, large and small, that help us meet our missions;

- Supporting the communities in which we work. We respect the people in our communities and protect the environment by embracing sustainable practices across our businesses;

- Generating long-term value for shareholders, who provide the capital that allows companies to invest, grow and innovate. We are committed to transparency and effective engagement with shareholders.

Each of our stakeholders is essential. We commit to deliver value to all of them, for the future success of our companies, our communities and our country.

11 The pandemic has caused many changes in the management of companies. Among these, we mention the modification to a large extent of the work conditions for managers and subordinates, new business difficulties, challenges, and opportunities with customers, suppliers, partners, bankers, and communities. These elements - and many others - make necessary new and performant managerial approaches in the relationships with all major endogenous and exogenous company stakeholders. Already, many specialists (Levenson, 2020; Teece, Raspin, \& Cox, 2020) are asking for new business models capable of attracting and using better competences and other resources of companies' stakeholders to the benefit of all parties involved.

12 In the context generated by COVID-19 crisis, certain specialists (Battilana \& Casciaro, 2021) argue the need to revamp boards in the companies and to give more power to employees and stakeholders. 


\section{Societal Arguments}

1 Harvard University mathematical biologist Martin Nowak, in 2006, discovered that natural cooperation is the third fundamental principle of evolution besides mutation and natural selection (Nowak, 2006).

2 Human beings are more cooperative and less selfish than most people believe. Organizations should help us embrace our collaborative sentiments (Benkler, 2011).

3 Societal requirements - formulated by many prestigious specialists based on valuable studies - propose to reframe capitalism in terms of stakeholder theory so that we come to see business as creating value for the stakeholder. We should move stakeholder theory to the centre of our thinking about business (Freeman, Harrison, Wicks, Parmar, \& De Colle, 2010).

4 More recently Edward Freeman and Heather Elms argued that the social responsibility of business is to create value for stakeholders, indicating customers, suppliers, employees, communities, and other shareholders (Freeman \& Elms, 2018).

5 Transition in the national and international economy, from competition between companies to competition between networks of companies' stakeholders. We have competing networks of stakeholders, where one competing network is in competition with others (Freeman et al., 2010). As a consequence, all relevant companies' stakeholders should be integrated in networks capable of competing successfully in local, regional, national, and international markets and environments.

6 Increase in the societal challenges and requirements versus companies in the context of the COVID-19 pandemic, which is a global societal crisis (Boston Consulting Group, 2020). In many countries, the state has acted in order to help companies to maintain supply chains, jobs, distribution networks, financial capacities, etc. Consequently, companies need to make many changes in their relationships with stakeholders involved in these processes suppliers, subordinates, customers, bankers, financial intermediaries, and others (see, e.g., BCG, 2020; Carlsson-Szlezac, Reeves, \& Swartz, 2020; Gjaja, Fæste, Hansell, \& Hohner, 2020; King, Wald, \& Manly, 2020; Waldron \& Wetherbe, 2020). Better and effective work and business relationships with major stakeholders will decrease the negative effects for companies, people, communities, businesses, and for the entire society in the future.

7 Corporate leaders, according to several reputed specialists, are rethinking the role of business in society. Companies need to add a lens to strategy setting, one that considers what we call total societal impact, which is the total benefit to society from company's 
products, services, operations, core capabilities, and activities (Beal et al., 2017).

8 In the context of the COVID-19 pandemic, the necessity to rethink the role of business in society has been emphasized by important organizations and specialists (BCG, 2020; Ghose, 2020; Levenson, 2020; Radjou, 2020).

9 In the context of the COVID-19 pandemic, even the replacement of capitalism with a new system called a "frugal economy" has been proposed. "A frugal economy centred on stakeholders" strives to create more economic, social, and ecological value while simultaneously wisely optimizing the use of all available resources. A frugal economy aims to do better with less, by making the most of all existing resources to maximize the value for all stakeholders (Radjou, 2020).

\section{Why Is Stakeholder Management Possible Now, in the Current Context?}

\section{Organizational Arguments}

1 Manifestation in companies of a very strong tendency of modernization of resources and activities is becoming and acting as ecosystems capable of, and open to, intensive innovation and change.

2 Transformation of an increasing proportion of companies into knowledge-based organizations, which possess the necessary vision and resources, especially the knowledge and information, to remodel them according to the new challenges, necessities, and opportunities.

3 Transformation of a large percentage of companies into learning organizations, amplifying substantially companies' and their managers' and executants' capacity to innovate and to remodel themselves.

4 Rapid digitalization of companies and the business environment, at a faster rate in the pandemic context, enhances and accelerates the use of knowledge and information, the communication and the consultation with the companies' stakeholders, both internal and external, actually and potentially.

5 Amplification of the information and knowledge is retained, shared, and used by the companies, their components, and the other stakeholders.

6 Proliferation at the level of companies focused on sustainability and corporate social responsibility, which make them more open and proactive to their stakeholders.

7 In the COVID-19 pandemic context, many companies, in every country, in order to survive and to continue their activities, have successfully made, in just a few months, many major changes, proving their remarkable organizational transformation capability. 
8 The pandemic crisis has emphasized companies' openness and willingness to change their receptiveness to new elements from both inside and outside the organization.

9 Increasing openness of companies to make organizational changes. According to a survey published by Harvard Business Review, in $2018,47 \%$ of companies reported that in order to survive they needed to reinvent their business every three years or less, and in 2020 , the number jumped to $58 \%$ (Zhexembayeva, 2020).

\section{Managerial Arguments}

1 The deep transformation of the management practices in numerous companies - corporations and large companies being in pole position - by quasi-continuous innovation and change. The transformation of management practice has been amplified and accelerated during the pandemic crisis.

2 The appearance in quite a large number of companies of new managerial dimensions - previsional, innovational, flexible, motivational, methodological, informational, formative, participative, systemic, and international - but still not sufficiently used and valorized by companies.

3 Seizing, taking into consideration and valorizing to a large extent by numerous companies' managers of the huge potential of the new organization resources - information, knowledge, and intellectual capital.

4 Awareness of a large number of managers of the company's many categories of stakeholders' existence and the major impact on it clients, suppliers, managers, executants, shareholders, investors, bankers, etc.

5 Discovering that managers can more effectively respond to hardship when they activate a shared emotional connection - referred to as "shared passion for place" - with the internal and external stakeholders. This represents a new path to organizational resilience (Hernandez, 2019).

6 Development in numerous companies of specific and effective managerial mechanisms for certain important stakeholder categories is very useful and capable of generating high performance. The most widely used and most performant of such mechanisms are the Customer Relationship Management (CRM) and Supply Chain Management (SCM).

7 Developments under environmental challenges and demands for certain stakeholder categories (e.g. local communities, company employees) are of specific managerial approaches with human and ecological dimensions like corporate social responsibility (CSR). 
8 The recent formulation of "the thesis that a combination of the focus on the management process with the stakes of the companies' stakeholders could represent to the present necessities and realities an alternative solution for obtaining sustainability" (Sadun, Bloom, \& Reenen, 2017).

9 Remodelling of the organization and employee culture, placing emphasis on the novelty, creativity, change, flexibility, participation, and adaptability amplified by the impact of the COVID-19 pandemic.

10 Manifestation, because of the mutations in the company environment associated with the transition to the knowledge- and digitalized-based economy and society - both in management science and management practice - of numerous innovative ideas and approaches, which continue to be amplified and diversified, in order to increase company performance and sustainability.

11 Identification of the necessity and possibility of radically remodelling an organization's management by the great number of renowned management scientists and top managers from prestigious companies and the formulation by them of appeals and urges in this respect. Among these, we mention the "Renegade Brigade" (Hamel 2009) and the strategic document adopted at the Davos Forum in 2017 called "The Compact for Responsive and Responsible Leadership - A Roadmap for Sustainable Long-Term Growth and Opportunity" (World Economic Forum, 2017). In the Renegade Brigade Manifesto (Hamel, 2009), 136 leading professors, consultants and managers from the USA, Europe, and Canada concluded that "the modern management" (management 1.0), which dates back to the late nineteenth century, has reached the limits of improvement. They have laid out a roadmap for reinventing management proposing to construct management 2.0, taking into consideration 25 management's grand challenges, which are summarized in Table 1.1.

According to the Renegade Brigade, the management should solve the following paradox: organizations must become more adaptable, innovative, and inspiring, without getting any less focused, disciplined, or performance oriented.

The strategic document "The Compact for Responsive and Responsible Leadership - A Roadmap for Sustainable Long-Term Growth and Opportunity" has been elaborated by 100 leading businesses and was finally adopted by all participants at the Davos Forum 2017 (World Economic Forum, 2017). According to this document, there is a need for a compact that recalibrates the relationship between public corporations and their major investors and conceives of corporate governance as a collaboration among corporations, shareholders, and other stakeholders working together to achieve long-term value and resist short termism. 
Table 1.1 Management's grand challenges

1. Ensure that the work of management serves a higher purpose

2. Fully embed the ideas of community and citizenship in management systems

3. Reconstruct management's philosophical foundations

4. Eliminate the pathologies of formal hierarchy

5. Reduce fear and increase trust

6. Reinvent the means of control

7. Redefine the work of leadership

8. Expand and exploit diversity

9. Reinvent strategy making as an emergent process

10. De-structure and disaggregate the organization

11. Dramatically reduce the pull of the past

12. Share the work of setting direction

13. Develop holistic performance measures

14. Stretch executive time frames and perspectives

15. Create a democracy of information

16. Empower the renegades and disarm the reactionaries

17. Expand the scope of employee autonomy

18. Create internal markets for ideas, talent and resources

19. Depoliticize decision-making

20. Better optimize trade-offs

21. Further unleash human imagination

22. Enable communities of passion

23. Retool management for an open world

24. Humanize the language and practice of business

25. Retrain managerial minds

Adapted from "Moon Shots for Management" by G. Hamel, 2009, Harvard Business Review, 87(2), 91-98. Retrieved from https://hbr.org/2009/02/moon-shots-for-management

Disagreement among stakeholders is best resolved in a transparent and respectful manner, de-escalating conflictual stances wherever possible. Each manager participant as a responsive and responsible leader has undersigned and committed to acting within the remit of his/her responsibilities, duties, and influence to promote meaningful engagement between the board, investors, and other stakeholders who builds mutual trust and effective stewardship, and promotes the highest possible standards of corporate conduct, and to implement policies and practices within the organization that drive transformation towards the adherence to long-term strategies and sustainable growth for the benefit of all stakeholders.

12 Enhancement of the managers' professionalization trend: professional manager possesses the high management and business knowledge level and a vision focusing on change, innovation, and participation, being capable to initiate and practice a new management type in the relationship with the companies' stakeholders, and valorizing their large potential in a win-win approach. The companies managed by 


\section{Instead of Introduction}

high-level professional managers have been able to face much better the COVID-19 pandemic challenges and threats and to "catch" and use better the new opportunities.

13 Development in the COVID-19 pandemic context of new managerial approaches regarding the company strategy, leadership, management of human resources, organizational culture, CRM, SCM, and others allows the company management to cooperate better and in a more performant manner with many major internal and external stakeholders - managers, subordinates, suppliers, customers, local communities, state authorities, etc. Among these new or substantially remodelled concepts and approaches, we mention the HEART framework (Waldron \& Wetherbe, 2020), an agile strategy (Heichler, 2020; Romeo, Moukanas, \& Rung, 2020; Teece, Raspin, \& Cox, 2020), resilience (Chaturvedi, Dey, \& Singh, 2020; Kaplan, 2020; Levenson, 2020), adaptive leadership (Ramalingam, Nabarro, Oqubay, Carnall, \& Wild, 2020), contingency planning (Levenson, 2020), transformational response (King et al., 2020), and multistakeholder capitalism (Romeo et al., 2020).

\section{Societal Arguments}

I This category of arguments is represented firstly by tendencies in an organizational environment that enable and make possible the implementation of stakeholder-based management. They are presented largely in Chapter 3 of this book. Here we just enumerate them:

1 Increase of business environment complexity, dynamism, and volatility.

2 Economy and society digitalization.

3 Work intellectualization.

4 Internationalization of all activities.

5 Multiculturalization of the labour force.

6 Nanotechnologization and biotechnologization.

7 Comprehensive networking in the society and economy.

8 Sustainable ecologization.

9 Intensification and diversification of state interventions in the economy.

10 Development of a powerful educational-formative dimension.

11 Multidimensional remodelling/reshaping of the markets.

Some of these trends are very complex, influencing not only the possibility of company management focusing on the stakeholders but also the need to do this in order to survive and be sustainable.

II From a societal point of view, the COVID-19 pandemic has increased the awareness of the society regarding the need to make 
profound changes in all its components, including the business environment and companies. Because of this, the society is more open to profound changes in all fields. Moreover, many specialists (Narayandas, Hebbar, \& Li, 2020; Romeo et al., 2020; Tarabishy \& Carayannis, 2020) have stressed that given more attention and consideration to stakeholders represents the main option to remodel society, business, and especially companies. The Global Risks Report 2020, presented at the World Economic Forum 2020 in Davos, stresses the need for a multi-stakeholder approach to addressing the world's greatest challenges (World Economic Forum, 2020). In fact, at the World Economic Forum's 50th annual meeting in Davos-Klosters, the focus was "Stakeholders for a cohesive and sustainable world".

III More than this, according to Joly (2021) - one of the best American companies CEO - has started stakeholder era, in which we need a refoundation of business and capitalism, and business leaders who prioritize common good and recognize the humanity of all stakeholders.

\section{References}

Bailey, A., Reeves, M., Whitaker, K., \& Hutchinson, R. (2019). The company of the future - Winning the '20s. Retrieved from https:/www.bcg.com/ publications/2019/company-of-the-future.aspx

Battilana, J., \& Casciaro, T. (2021). Power sharing can change corporations for the better. Harvard Business Review. Retrieved from https://hbr.org/2021/05/ power-sharing-can-change-corporations-for-the-better

Beal, D., Eccles, R., Hansell, G., Lesser, R., Unnikrishnan, S., Woods, W., \& Young, D. (2017). Total societal impact: A new lens for strategy. Retrieved from https://www.bcg.com/publications/2017/total-societal-impact-new-lensstrategy.aspx

Benkler, Y. (2011). The unselfish gene. Harvard Business Review, 89(7-8), 76-85.

Boston Consulting Group. (2020). COVID-19 BCG perspectives series: Facts, scenarios and actions for leaders. Retrieved from https://mediapublications.bcg.com/BCG-COVID-19-BCG-Perspectives-Version13.pdf

Carlsson-Szlezac, P., Reeves M., \& Swartz, P. (2020). Understanding the economic shock of coronavirus. Harvard Business Review. Retrieved from https:// hbr.org/2020/03/understanding-the-economic-shock-of-coronavirus

Chaturvedi, H., Dey A. K., \& Singh, N. (2020). Coping with COVID-19. Global Focus the EFMD Business Magazine. Retrieved from https:/ www.globalfocusmagazine.com/coping-with-covid-19/

Coghlan, D. (2016). Inside organizations: Exploring organizational experience. London, UK: Sage Publications. 10.4135/9781526402424

Crane, A., Palazzo, G., Spence, L. J., \& Matten, D. (2014). Contesting the value of “creating shared value." California Management Review, 56(2), 130-153. $10.1525 / \mathrm{cmr} .2014 .56 .2 .130$ 
Freeman, R. E. (2017). Foreword. In J. Andriof, S. Waddock, B. Husted, \& S. S. Rahman (Eds.), Unfolding stakeholder thinking: Theory, responsibility and engagement (Vol. 1, pp. 7-8). New York, NY: Routledge.

Freeman, R. E., \& Elms, H. (2018). The social responsibility of business is to create value for stakeholders. MIT Sloan Management Review. Retrieved from https://sloanreview.mit.edu/article/the-social-responsibility-of-business-is-tocreate-value-for-stakeholders/

Freeman, R. E., Harrison, J. S., Wicks, A. C., Parmar, B. L., \& De Colle, S. (2010). Stakeholder theory: The state of art. New York, NY: Cambridge University Press.

Ghose, S. (2020). Are you ready for the quantum computing revolution? Harvard Business Review. Retrieved from https://hbr.org/2020/09/are-youready-for-the-quantum-computing-revolution

Gjaja, M., Fæste, L., Hansell, G., \& Hohner, D. (2020, April 16). COVID-19: Win the fight, win the future. Boston Consulting Group. Retrieved from https://www.bcg.com/en-hu/publications/2020/covid-scenario-planning-winning-the-future-series

Hamel, G. (2009). Moon shots for management. Harvard Business Review, 87(2), 91-98. Retrieved from https://hbr.org/2009/02/moon-shots-for-management

Heichler, E. (2020). Seize the moment. MIT Sloan Management Review. Retrieved from https://sloanreview.mit.edu/article/seize-the-moment/?og=Fall $+2020+$ Issue + Horizontal

Hernandez, M. (2019). A shared passion for place can make a business more resilient. MIT Sloan Management Review. Retrieved from https://sloanreview. mit.edu/article/a-shared-passion-for-place-can-make-a-business-more-resilient/

Ignatius, A. (2019). Profit and purpose. Harvard Business Review, 97(2), 10.

International Council for Small Business. (2019). ICSB's humane entrepreneurship initiative adopted by CEOs of nearly 200 companies. Statement on the purpose of cooperation. Retrieved from https://icsb.org/200ceos/

Joly, H. (2021). How to lead in the stakeholder era. Harvard Business Review. Retrieved from https://hbr.org/2021/05/how-to-lead-in-the-stakeholder-era

Kaplan, S. (2020). Why social responsibility produces more resilient organizations. MIT Sloan Management Review. Retrieved from https://sloanreview.mit.edu/ article/why-social-responsibility-produces-more-resilient-organizations/

King, K., Wald, D., \& Manly, J. (2020, April 21). Advantage beyond the crisis. Boston Consulting Group. Retrieved from https://www.bcg.com/en-hu/ publications/2020/building-business-advantage-beyond-covid-19-crisis

Levenson, A. (2020). A long time until the economic new normal. MIT Sloan Management Review. Retrieved from https://sloanreview.mit.edu/article/along-time-until-the-economic-new-normal

Narayandas, D., Hebbar, V., \& Li., L. (2020). Lessons from Chinese companies' response to Covid-19. Harvard Business Review. Retrieved from https:// hbr.org/2020/06/lessons-from-chinese-companies-response-to-covid-19

Nicolescu, O., \& Nicolescu, C. (2017). New approach - Quadrangle of knowledge based sustainability. Proceedings of International Conference "Knowledge-Based Organization,” 23(1), 411-417. Retrieved from https://www.researchgate.net/ publication/318732098_New_Approach_-_Quadrangle_of_Knowledge_Based_ Sustainability. doi:10.1515/kbo-2017-0068 
Nowak, M. A. (2006). Evolutionary dynamics: Exploring the equations of life. Cambridge, MA: Harvard Business Press.

Post, J. E., Preston, L. E., \& Sachs, S. (2002). Redefining the corporation: Stakeholder management and organizational wealth. Stanford, CA: Stanford University Press.

Radjou, N. (2020). The rising frugal economy. MIT Sloan Management Review. Retrieved from https://sloanreview.mit.edu/article/the-rising-frugal-economy/

Ramalingam, B., Nabarro, D., Oqubay, A., Carnall, D. R., \& Wild, L. (2020). 5 principles to guide adaptive leadership. Harvard Business Review. Retrieved from https://hbr.org/2020/09/5-principles-to-guide-adaptive-leadership

Ready, D. A., Cohen, C., Kiron, D., \& Pring, B. (2020). The new leadership playbook for digital age. MIT Sloan Management Review. Retrieved from https://sloanreview.mit.edu/projects/the-new-leadership-playbook-for-thedigital-age/?gclid=CjwKCAjwg6b0BRBMEiwANd1_SE8dUmZetK_peLCkKBI6abknYo6vYcKUtSDNbE_MYo5CTuqs4SF6yRoCxlwQAvD_BwE

Romeo, J., Moukanas, H., \& Rung, G. (2020). The age of accelerating strategy breakthroughs. MIT Sloan Management Review. Retrieved from https:// sloanreview.mit.edu/article/the-age-of-accelerating-strategy-breakthroughs/

Sadun, R., Bloom, N., \& Reenen J. V. (2017). Why do we undervalue competitive management? Harvard Business Review, 95(5), 120-127.

Schein, E. H., \& Schein, P. A. (2019). A new era for culture, change, and leadership. MIT Sloan Management Review, 60(4), 52-58.

Schwartz, J., Hagel III, J., Wooll, M., \& Monahan, K. (2019). Reframing the future of work. MIT Sloan Management Review. Retrieved from https:// sloanreview.mit.edu/article/reframing-the-future-of-work/

Tarabishy, A. E., \& Carayannis, E. (2020, September 12). Democratization of knowledge. International Council for Small Business. Retrieved from https:// icsb.org/democratizationofknowledge/

Teece, D. J., Raspin, P. G., \& Cox, D. R. (2020). Plotting strategy in a dynamic world. MIT Sloan Management Review. Retrieved from Review Special Collection: https://sloanreview.mit.edu/article/plotting-strategy-in-a-dynamic-world/

Waldron, T., \& Wetherbe, J. (2020). Ensure that your customer relationships outlast coronavirus. Harvard Business Review. Retrieved from https:// hbr.org/2020/04/ensure-that-your-customer-relationships-outlast-coronavirus

Weill, P., \& Woerner, S. L. (2018). Surviving in an increasingly digital ecosystem. MIT Sloan Management Review, 59(2), 26-28.

World Economic Forum. (2017). World Economic Forum annual meeting. The compact for responsive and responsible leadership - A roadmap for sustainable long-term growth and opportunity. Retrieved from https://www.weforum.org/ events/world-economic-forum-annual-meeting-2017

World Economic Forum. (2020). The global risk report 2020. Retrieved from http://www3.weforum.org/docs/WEF_Global_Risk_Report_2020.pdf

Zhexembayeva, N. (2020). 3 things you're getting wrong about organizational change. Harvard Business Review. Retrieved from https://hbr.org/2020/06/3things-youre-getting-wrong-about-organizational-change 